Benito Arruñada 1

\title{
Managing Competition in Professional Services and the Burden of Inertia
}

\begin{abstract}
Published in Claus-Dieter Ehlermann and Isabela Atanasiu, eds., European Competition Law Annual 2004: The Relationship between Competition Law and the (Liberal) Professions, Hart Publishing, Oxford and Portland Oregon, 2006, 51-71.
\end{abstract}

\section{Introduction}

Professional services require certain organizational patterns in order to avoid information asymmetries and external effects. These same patterns are used within production structures involving various degrees of monopoly. However, competitive restraints are justified today only when substantial external effects are clearly present, whereas information asymmetries hardly justify such restraints because reputational investments have become widespread in the economy and are relatively efficient in overcoming such asymmetries. As a consequence, innovation in the production of externalities can make competitive constraints unnecessary.

The rest of this work is divided in two parts. The first one discusses the problems of professions generally and the second focuses on two specific cases. Thus, section 2 identifies the characteristic situation of professional services, which is caused by the presence of information asymmetries when private services are offered, the presence of, or desire for, external effects and the reduction in costs that arises when the same professional provides both types of service. Section 3 argues that in order to resolve the problems of information asymmetry, it is usually necessary to adopt a series of organizational patterns: deferred and variable compensation in line with the professional's and others' conduct, and self-selection of professionals having ideal characteristics. Section 4 outlines a scheme for assessing the situation of professions from the point of view of economic policy.

The second part encompasses sections 5 and 6, which analyze the situation of two professions - pharmacies and conveyancers - , which are now the most highly regulated in Europe, perhaps because they are also the oldest (Monti, 2003, 2). A similar conclusion is reached in both cases, namely, that historical justification for a corporatist organization of these

1 Department of Economics and Business, Universitat Pompeu Fabra (Trias Fargas, 25; E-08005Barcelona. E-mail: benito.arrunada@upf.edu). The author thanks Jürgen Backhaus, Cándido Paz-Ares, Frank Stephen and participants at several academic meetings, including the Ninth EU Competition Law and Policy Workshop for their comments to previous versions of this work. Usual disclaimers apply. This project has received financial support from the MCYT, an agency of the Spanish Government, through grants SEC99-1191 and SEC2002-04471-C02-02. 
services is no longer valid and that, as a consequence, both professions now offer inappropriate services for the current situation of demand and technology. Liberalization is therefore advisable, especially for the most standard services.

\section{Nature of professional services}

Professional services have two properties: information asymmetry between providers and customers and the production of external effects. Many other goods and services share these two properties but their extent in professional services leads to special problems which can only be resolved by adopting special organizational formulas.

\section{II.1. Information asymmetry}

Production of professional services suffers from serious information asymmetries for two reasons. Firstly, such services often involve application of the professional's human capital in order to judge individual cases. Secondly, results are extremely difficult to assess. Professional work can therefore be seen as the application of specialized human capital to the solution of individual cases, leading to a product that is difficult to evaluate. Each of these elementsassessment, a personalized product that is difficult to observe and intense human capitalinvolve specific contractual problems. The fact that they come together compounds the difficulties which characterize professional services.

Moreover, transactions are often non-repetitive and atypical. Many professional services present "search" attributes, the quality of which might be known prior to purchase or consumption, as well as "experience" attributes, whose quality can only be appreciated during or after consumption, as with many other services (Nelson, 1970). In addition, the most outstanding characteristic is the presence of "credence" attributes, whose quality can never be fully appreciated (Darby and Karni, 1973).

Other complications relate to the heterogeneity of demand, the high degree of specific human capital, and the presence of professional judgment.

a) Heterogeneous demand. Professional services are individual to the extent that each customer demands and receives different services. Even when cases share certain elements, these usually appear in different combinations, so that service standardization is often impossible or at least unadvisable. Although to some extent the development of routines and protocols assists in standardization, this is often a source of problems as it affects quality as perceived by the customer. ${ }^{2}$ Control can only exist in the form of

${ }^{2}$ Standardization is curbed not only by technological but also by psychological considerations. This was learnt several decades ago by non-professional service firms which pioneered "service 
evaluation of the productive process rather than of its results, using implicit motivation mechanisms through moral indoctrination, quasi-rents and self-selection.

b) Specific human capital. Essentially, professionals have to invest now in knowledge needed to resolve problems in the future. As a result, their decisions must not be seen as if they were just supplying labor, in the neoclassical sense. They have to be seen instead as investors. Furthermore, not only is compensation deferred but also investments are specific because professional knowledge has practically no value outside the profession. As a result, expected returns and the risk of expropriation play important roles in the long term and must be taken into account when professional activities are regulated or managed.

c) Professional judgment. An essential part of professional work involves judging individual cases, often urgently, and using information which is imperfect but can be improved at an additional cost in time and money. This judgement is mostly individual, with each professional taking decisions alone. Even when the production processes of many professional services involve teams in which there is a degree of mutual control, a large degree of individual discretion is applied.

All these circumstances create a situation in which there are substantial information asymmetries amongst those providing, organizing, regulating and using professional services, making it very difficult to contain conflicts of interest among them. For example, it is difficult for professionals to guarantee the optimal level of quality. When a professional does not provide optimal quality, she will obtain a short-term gain in exchange for an uncertain possibility of a future sanction. Supervision of service quality is difficult for other participants, whether they are customers, regulators, professional associations or other professionals, even within a single firm. Any subsequent review of quality will be, for instance, subject to the typical problem involved in assessing decisions taken in a context of uncertainty and imperfect information. The decision being assessed might have been right with the information available, although information gathered subsequently shows that it was wrong under the actual circumstances. (There is, as a consequence, a substantial risk of falling into the traps of hindsight bias ${ }^{3}$ ). A main problem of this type of service is therefore that of creating mechanisms for safeguarding or ensuring quality under unfavorable circumstances because verification of contractual performance by third parties and even by the interested parties themselves is often only possible in the long term.

\section{II.2. External effects}

So far we have considered the problem of the information asymmetry that exists between the suppliers and customers of private services. This is a typical bilateral agency relationship in which the supplier acts as agent for a principal who is the customer. In fact, however, it is more

industrialization". Many management experts supported this wave of industrialization, following Levitt $(1972,1976)$, until the limitations of this "manufacturing" approach in service management became clear (Fitzsimmons and Sullivan, 1982).

${ }^{3}$ Evidence on hindsight bias, a phenomenon first described by Fischhoff (1975), has been accumulating over time (Christensen-Szalanski and Willham, 1991). 
complex than this. Not only because there are usually other individuals involved, such as partners, regulators, informers, assessors, etc., reducing the bilateral nature of the transaction, but also because the provision of private services usually goes together with external effects or, in other words, with the provision of public services. Hence, the relationship becomes a multilateral one, involving greater complexity and potential for conflict.

These externalities stem from both the nature of the private services and from political decisions which oblige certain private service providers to also provide certain public services. The underlying economic rationale is the same in both cases - the production of private and public services by a single professional implies economies of scope or joint production. In other words, it is less costly if a single professional produces both private and public services on the same cases. The reason lies in the use of joint informational and contractual resources. On the one hand, the provision of private and public services usually requires the same information, both general — the human capital or general knowledge to be applied — and specific — relating to the customer or the case in question. On the other, similar problems arise with both types of service regarding contractual safeguards. It is necessary and costly to ensure that the professional fulfils the contract. Such problems require the use of safeguard mechanisms which, being costly, should be used to ensure fulfillment over the widest possible range of services.

Professional services result in a wide variety of external effects with an element of so-called "gatekeeping". This gatekeeping entails authorizing a third party — the gatekeeper, who has other functions, in this case the provision of private services, so is free to refuse to cooperate and, by doing so, will prevent or curb unlawful conduct. ${ }^{4}$ The concept is a broad and imprecise one. For Kraakman, examples of gatekeepers include accountants and lawyers in securities transactions, doctors, pharmacists, employers' vicarious liability, bouncers, sellers of firearms, advertising agencies, insurance companies in environment regulation, common law duties of lenders and corporate directors, tax preparers and practitioners, and chaperones. Most lawyers, including civil law notaries, carry out a dual role which involves not only the provision of private services but also acting as gatekeepers in this sense. English barristers, for example, act as agents for the courts. ${ }^{5}$ Gatekeeping is not the only type of external effect, however. For example, litigation lawyers contribute substantially to judicial rulings and the quality of their services is therefore important in the creation of case law.

Assigning the production of externalities to professionals reaches economies of scope but poses a serious problem in that, in principle, the professional has no incentives to produce the externalities, as these are services for which she is not paid and for which she might even have to incur a certain cost. As a gatekeeper, the professional is an agent for two principals (her customer and society) whose interests are often in conflict. In order to resolve this satisfactorily,

4 This figure of the gatekeeper as a guardian of law has been described by Kraakman (1986), who defines his liability as

liability imposed on private parties who are able to disrupt misconduct by withholding their cooperation from wrongdoers.

Gatekeeper liability is distinguished by the duty that it imposes on private "gatekeepers" to prevent misconduct by withholding support. This support-usually a specialized good, service, or form of certification that is essential for the wrongdoing to succeed-is the "gate" that the gatekeeper keeps (Kraakman, 1986, 53-54).

5 See, for example, Posner (1995b) for an argument along these lines. 
there must be strong incentives to make the professional independent from the customer who is paying her even considering that, if the services are refused, she risks losing the customer. Achieving sufficient incentives for such a high degree of independence will be costly. In particular, it will require suppressing or restraining competition. The efficiency and cost of standard organizational patterns, as described in the next section, must be evaluated in this context.

\section{Organizational patterns}

Because of the characteristics analyzed in the previous section, professional services have to be produced and sold within organizational formulas - such as professional associations, professional firms or hybrids, such as health maintenance organizations - which are quite different from those of neoclassical abstractions of firms and markets. In addition, these formulas are similar in liberal professions and professional firms, another reason why competition policy should focus more on professional firms than on traditional professions.

\section{III.1. Common patterns}

The common organizational structure for all professional activities, whether in competition or not, is characterized by incentives for the professionals themselves and by the process of selfselection which such incentives generate. Three basic features are present: (a) a deferred compensation system, with high penalties in case of non-compliance with professional standards; (b) variability in earnings, promoting productivity and mutual control; and (c) a process of selfselection introducing a certain degree of automatic control.

a) Quasi-rents. Professionals are paid above their highest opportunity earnings during the most important stage of their career, with the professional or the firm receiving a quality premium or "quasi-rent", ${ }^{6}$ which compensates for prior investments. This type of compensation motivates individual professionals and firms to comply, provided there is a positive probability of losing the quasi-rents in case of non-compliance. In the absence of competition, such quasi-rents are structured in the form of professional entry barriersentry examinations, hierarchies, and apprenticeships - which require a large initial investment. On the other hand, in firms that compete with others in providing professional

6 Studies on how the expectation of receiving a flow of quasi-rents in the future automatically encourages producers to preserve the quality of the products or services they provide, which go back to Becker and Stigler (1974), were developed by Klein and Leffler (1981), Williamson (1983) and Shapiro (1983) and applied to labor in models on deferred compensation (Lazear, 1979) and efficient wages (Shapiro and Stiglitz, 1984). 
services - as in consulting, auditing, law, investment banking or, even, higher education ${ }^{7}$ - these quasi-rents result from organizational decisions on personnel selection, task allocation, promotions and compensation profiles. ${ }^{8}$ In both cases, however, compensation is below opportunity earnings during the initial period and above it afterwards.

b) Variable compensation. The fact that earnings vary positively with the professional's conduct in aspects in which competition is accepted and negatively with the conduct of colleagues in areas in which it is prohibited (basically with their bad conduct) favors the achievement of some efficiency objectives in two ways. Firstly, it promotes productivity in areas in which there is competition. Secondly, it encourages mutual control so that competition is restricted to such areas.

c) Self-selection. Finally, the presence of such incentives usually leads to a process of selfselection of a certain type of person, those who appreciate working under such restrictions and with such payment patterns. Mainly, deferred compensation encourages entry by people having a low subjective discount rate. To the extent that preferences differ amongst individuals and are constant throughout their lives, this self-selection favors the entry of professionals having preferences that are well suited for rejecting temptations of bad professional practice, which often bring benefits in the short term only, with possible penalties being paid only in the future.

Revealingly, the structure of such incentives is similar, whether they result from an internal decision by organizations which compete freely in the provision of professional services (auditing, consultancy, law firms) or from the competitive constraints faced by liberal professionals practicing independently as individuals. When competing firms provide the services, such incentive patterns are not seen as restrictions to competition but as professional "careers" in a sort of internal labor market. In many cases this distinction is more legal than economic, as with the treatment of vertical restrictions when the distinction depends on whether distributors are vertically integrated with the producer or not.

In practice, however, there is more often a radical difference. While producers and distributors of non-professional goods usually compete with other producers and distributorsthis being a necessary condition if the vertical restrictions are to be considered favorably-, professional associations almost always act as monopolies. Economic justification for the restrictions in the latter case therefore requires two additional conditions. First, the existence of substantial external effects as produced by the incentive structure created by the restrictions, because the problems of information asymmetry can be resolved using contractual safeguards that are freely drawn up by competing private organizations. ${ }^{9}$ Second, it must be less efficient to

7 See, amongst many others, Fama and Jensen (1983a, 315-17; and 1983b, 334-37), Gilsonand Mnookin (1985), and Carr and Mathewson (1990).

8 A remuneration system that has these properties is that of federal judges in the US, whose payment is deferred in the form of a generous pension. See Posner (1995b, 109-44).

${ }^{9}$ An example are the contracts being used in the US health sector in the form of Health Maintenance Organizations or "HMOs". This unusual type of franchise uses various organizational patterns such as contracts for assistance from a closed list of doctors, supervision of doctors and vertical integration, some of the serious conflicts of interest between doctors, 
produce such external effects under an alternative regime of regulated competition between firms whose employees and partners are motivated according to the standard professional patterns. ${ }^{10}$ This might be the case when such a regime requires a high degree of supervision and regulation, and public administrations are not capable of providing it efficiently.

III.2. The power of competition between professional firms

Much of the discussion on professional regulation would be more relevant for policymaking in the $19^{\text {th }}$ than in the $21^{\text {st }}$ century because it ignores the fact that professional services are, or (in the absence of competitive restraints) would be, provided through professional firms. The presence of professional firms redefines the problems, provides effective solutions and requires a broader regulatory perspective for professional services.

Firstly, professional firms are better able to safeguard their transactions with reputation, repetition and a longer horizon. Secondly, agency problems between the firm and both its professionals and its customers become the key issue. ${ }^{11}$ Thirdly, the presence of firms combines the issue of professionals' regulation with the more basic matter of freedom of contract.

This last point requires a short digression.

The commonality of organizational patterns within traditional liberal professions and professional firms freely competing in the market also holds an important lesson for competition policy in this field. One of the main problems of self-regulation amongst professionals is that there is no competition between self-regulatory structures, as each profession enjoys a monopoly over a certain market. The use of organizational devices to avoid information asymmetries and control quality indicates that professional firms are also self-regulatory structures and thus, when competing with each other, they in fact create competition between regulatory frameworks.

The legal environment does not always help firms to solve the agency problems, mainly because during the $20^{\text {th }}$ century judges have been increasingly allowed to regulate contracts (Arruñada and Andonova, 2004), impeding the development of private legal orders by firms. Without this constraint, professional firms would work more as private and competitive jurisdictions, providing the most viable form of competitive self-regulation, with each firm acting as its own self-regulator each time it changes its internal rules or its product guarantees. For example, if competitive firm $A$ provides a service to client $B$, in order to motivate itself and to control its professionals, the firm could promise full satisfaction or the money back.

patients and insurance companies which have led to this sector being considered as full of "market faults". See Feldstein (1988, 314-38) for an introduction.

10 This may be the situation of financial auditors who compete both through professional associations and through firms and as individual professionals. See especially Watts and Zimmerman (1979; 1986, 179-99 and 222-43), and Arruñada (1999a, 2000).

11 On the other hand, competition between firms should not be a particular problem in professional services, because, being intensive in human capital and being human capital mobile, firms restructuring and entry is relatively easy. 
Depending on the legal system, the mechanism may be allowed to function under second party enforcement or may be mandatorily supervised by the courts. This defines two situations for cases in which a customer $B$ claims to be unsatisfied and provider $A$ rejects the claim because he thinks $B$ is abusing the guarantee and acting opportunistically. If the case is subject to a court decision (mandatory third party enforcement) and the judge rules for $B$, this may hinder the development of private legal orders, in which firms would act as judges, controlled by reputation and competition. The tendency of judges to intervene in all areas irrespective of the contractual assignment of decision rights (in which $A$ is granted the right to freely decide on the merits of $B$ 's claim) thwarts competition between private legal orders which could otherwise provide the most effective solutions for such difficult relationships. In sum, the main issue is to what degree firms should be allowed to act as judges within relational contracting structures, and how this competition among contractual frameworks could be made easier, or at least not be hampered, by legal institutions. ${ }^{12}$

\section{IV.Assessment of competitive restraints in the professions}

The use of similar organizational patterns by firms providing professional services in competitive markets, by professional associations and even by some civil service systems indicates that such patterns are likely to be efficient or at least, to some degree, adaptive. It also justifies a case-by-case analysis of the possible benefits and monopoly costs present in the various types of institution and market structures in the professional service sector. Such an analysis must be based on its own merits, like the type of analysis which is increasingly being carried out on the vertical restrictions between producer and distributor. For vertical restrictions, both the economic literature and, increasingly, anti-trust authorities prefer to study each case separately, applying a rule of reason and rejecting rigid, per se exclusion of certain general patterns, such as territorial exclusiveness. In professions, it is also best to adopt a case-by-case approach, analyzing each profession separately. A study of each of these institutions must take into account the possible existence of external effects and the cost of alternatives for dealing with them; also, problems of information asymmetry, considering how they can be mitigated or resolved both now and in the future within the new framework being considered. In other words, on the one hand policy-makers have to define which services they want professionals to produce and which they want regulators and civil servants to produce. On the other, they have to consider achieving a transition that will avoid unintentionally increasing entry barriers and creating uncontrolled regulatory bodies, while encouraging the development of spontaneous, contractual safeguards for problems of information asymmetry.

12 This kind of judicial activism is not the only barrier. Another example are the barriers on multidisciplinary practice, epitomized in Europe by the Wouters ruling of the European Court of Justice, which allows national rules forbidding lawyers working with auditors to protect the proper practices of the legal profession and is been followed by the Proposal for a directive on professional services in the internal market (COM(2004)2). On multidisciplinary practice, see Arruñada (1999b). 
Ideally, economic policy should not only examine the situation in the appropriate professional sector but should also compare its efficiency with alternative formulas. Both tasks are difficult, however, as shown by the following analysis.

IV.1. A check-list for analyzing a profession

Analysis of regulation of a specific profession should include at least a thorough review of the objectives of the profession regarding information asymmetry and external effects, its real efficiency in achieving such objectives and the cost of achieving them.

Efficient analysis of the attributes or nature of the service requires an understanding of the productive and contractual technology involved. Initially, the attributes of information asymmetry and quality in the professional field might be considered of secondary importance today to external effects, because modern markets have been shown to have greater capacity than the State for resolving problems of information asymmetry, partly because of durable firms with considerable reputational investments. In other words, restricting competition within a profession makes more sense to the extent that the profession provides public services involving external effects. The possible costs of such patterns caused by the restriction of competition may be negligible in comparison with the greater costs that would be generated if such services were provided by civil servants or even by professional firms in a highly regulated environment.

Secondly, study of the efficiency with which the service is provided within a real or hypothetical organizational formula will generally focus on the incentives created by the collection of quasi-rents through deferred payment and rents, variability of earnings and the consequent processes of self-selection. In this set-up, it is especially important to assess whether the sanctioning mechanisms needed to make quasi-rent incentives really effective actually work; whether variability of earnings is sufficient to promote cost reduction and mutual quality control; and whether the process of self-selection favors the entry of the type of personnel most suitable for the functions in question and for the development of corporate control patterns.

Finally, the costs generated by competitive restrictions must be considered. This assessment must include the loss of welfare caused by the higher prices and the resulting lower quantities; the increase in costs caused by competitive restrictions, which becomes more marked when innovation is restricted and, finally, rent seeking costs which largely depend on how the entry mechanism is designed. Of fundamental importance are indications on effective elasticity of demand, which will be low when there are legal restrictions making consumption compulsory; the rate of return on the whole professional career, with the data on annual earnings being of little consequence; and the design of mechanisms for taking decisions on price-fixing and entry controls. It is also important to determine to what extent the regulator is 'captured', whether there is sufficient separation between regulators and regulated and whether citizens are correctly informed. ${ }^{13}$ Finally, it is important to analyze entry mechanisms and the costs of rent seeking, at both the entry and rent distribution stages.

13 For instance, when professionals act as tax collectors, information asymmetries often lead citizens to incorrectly value professionals' earnings. 
IV.2. Comparing organizational possibilities

It is difficult to compare possible solutions because there are certain aspects about which little is known. Three main problems are: too narrow a focus on one of the dimensions of competition, with price fixing or freedom of entry often being considered the only relevant competitive variable; the invisibility of solutions that have not surfaced because they require technological innovations that are inaccessible within the current corporative structures; and the need to reach a certain equilibrium between the risks of regulatory capture and regulatory opportunism.

\section{Emphasis on one dimension of competition}

Many deregulating proposals do not attempt to understand the nature of the services and just focus on one of the variables that may be useful in institutional design - either the intensity of price competition or freedom of entry. A focus on price competition often disregards its implications for the nature of the service that can be produced in a specific institutional order and the concentration process that is often generated. Similarly, freeing entry under fixed prices (as sometimes occurs and has often been proposed for pharmacies) disregards substantial costs (such as those related to dissipation of rents used to keep marginal pharmacies open and thus fully cover a given territory).

However, legislators may change not only the intensity of competition but also its dimensions, as well as product definition and the degree of integration. Explicit consideration should be given to these possibilities in order to avoid the risk of adopting adventurous reforms which may have doubtful results and may end up in situations that are regulated in an even more deficient way. ${ }^{14}$ Otherwise, the exclusion of external effects from the professional's task usually means that production or control has to be carried out by new regulations and regulators whose organization is by no means totally efficient. The costs of these new regulations are usually under-estimated, despite the tendency of deregulation measures to quickly end up as just a different way of regulating an economic sector.

\section{Dynamic analysis: the relativity of technological determinants}

The discussion so far has assumed a given technology and has analyzed the influences it creates. But technology in any industry changes as a consequence of innovation. In this dynamic context, the technological restrictions analyzed in the second section should be partially seen as the result and not only the cause of the competitive restrictions present in markets for professional services. It is no coincidence that typical restrictions in professional sectors remove

14 On the mixed results of liberalization efforts, see, for example, Evans, Laurila and Paserman (2004, 11-12). 
incentives for innovation (Arruñada, 1992), in order to protect professionals' quasi-rents and to recover investments in human capital. These systems involve a certain cost in terms of slow, limited innovation.

This lack of innovation can be expected to vary greatly from activity to activity and the technological gap with the rest of the economy to widen as external innovation increases. There are clear signs that this may be a problem, with potential technology being applied slowly due to the organization of some professional sectors. And this is applicable to both production and contractual technologies. In the case of medicine, for example, an increasing number of therapeutic and diagnostic techniques now require knowledge that is not strictly medical but doctors are still required for using them.

This is also true for contractual technologies because, as argued above, greater development of brands and commercial names makes it possible for free action in the market to resolve the problems of information asymmetry between the professional and the customer. The justification for competitive restrictions based on information asymmetry was clearer in the past, when the participants in commercial transactions were mostly individuals. ${ }^{15}$ In many new sectors, the free market has now shown its capacity for resolving more serious information asymmetries than those existing in many sectors that were traditionally professional. ${ }^{16}$ For example, compare the design, production and sale of automobiles and buildings.

Consequently, there seems to be a substantial degree of inertia in the assignation of competitive or corporate organizational patterns to different sectors depending on their situation in the past. In many cases, corporate patterns seem to be little more than a historical remnant for which there is little justification today. The cognitive problem in such cases, however, is complex. Although, ideally, public policy should apply reforms allowing for the evolution of corporate sectors in line with new possibilities for market operation which have opened up but are mostly unknown, such reforms run the risk of destroying the efficiency of the traditional system. The transition therefore becomes risky and may even cause a reaction towards new restraints on competition.

\section{The need for balance between regulatory capture and opportunism}

In any of the organizational possibilities - from the regulation of private suppliers to management by civil servants - preserving the long-term incentives which are characteristic of professional services requires balancing two opposing dangers-opportunism by regulators (or managers) against professionals, and the capture of regulators by professionals.

a) Opportunism takes the form of imprudent or self-interested regulatory or managerial changes which, by bringing down prices, freeing entry, changing operating methods,

15 See, for similar conclusion, Stephen (2004), who emphasizes how in many markets customers are repeated purchasers and public bodies.

16 I understand "the market" here as an institutional reality, not as the neoclassical abstraction used in some economic analysis. In particular, controlling professionals in order to solve the problem of information asymmetry often requires creating a professional service firm. 
skipping promotions, reducing salaries, forcing early retirement, and so on, may expropriate earnings above what is obtainable outside the profession or the firm (the "quasi-rents" which compensate for investments made in the past). The risk is especially great when there is poor knowledge about the nature of the quasi-rents, which are often seen, especially by the general public, as a surplus salary or pure rent when they might be a return on a prior investment in human capital. Furthermore, expropriatory decisions can result from the shortsighted horizon of regulators and managers, inclining them to destroy the system of deferred payment, altering or introducing uncertainty into expectations of future remuneration and removing incentives for future investments, even when such a system is efficient.

b) There may also be capture of regulators and managers by professionals. This phenomenon may result in price rises or freezing of the supply with the resulting generation of rents or distribution amongst a smaller number of senior professionals. Wealth is thus transferred from customers and junior professionals to all or the most senior professionals, output falls, and possible candidates waste more resources in their attempts to enter the profession.

It is difficult to find a perfect solution to these problems because, while the introduction of greater self-regulation protects professionals' investments, it causes a greater risk of regulatory capture. However, it is important to provide guarantees that deferred compensation will be received in the future. Note that professional firms display several features that act as safeguards when using systems of this type. For instance, the recipients of quasi-rents are also the main decision-makers, as the longest-serving professionals are often partners in their firms. In the public area, we should therefore learn to consider this positive aspect of self-regulation, accepting some degree of regulatory capture to safeguard specific investments in human capital.

\section{IV.3. International comparisons}

A final word of caution is in order regarding the use of international comparisons, because of the interconnections between services provided by professionals and other institutions in the public sector. ${ }^{17}$ Professionals in different countries may be providing different services which require different organizational structures - that is, different competitive restraints. ${ }^{18}$ Evidence on differential regulation would therefore support a private interest explanation only if such differences in regulation are shown to be inconsistent with the different services being provided. Sections 5 and 6 analyze now the case of pharmacies and conveyancers.

17 This problem plagues the ambitious "law and finance" research program and its related initiatives, such as the World Bank's Doing Business (2004). See Arruñada and Andonova (2005, 239-46) for a detailed critical analysis.

18 These interconnections limit the value of arguments based on the differential constraints imposed on the same professions across a given set of countries, as in Monti (2003), and Paterson, Fink and Ogus (2003). 


\section{Pharmacies}

Like many other human activities, health care has undergone gradual specialization. A single individual, who often also acted as priest, once cared for the sick. Over the centuries, a range of specialists grew up - doctors, pharmacists, producers of medicines, nurses. Pharmaceutical service underwent two basic transformations. The first, when medical care was separated from the production of medicines, took place in ancient Egypt but the second, when the production of medicines was separated from distribution, only took place after the First World War. ${ }^{19}$

This historical sequence suggests that the survival of a profession devoted to dispensing might well be an anomaly. Perhaps what was regulated at the time was not so much the activity of distribution as that of production by pharmacies. Yet medicines are no longer produced by hand in pharmacies but industrially in factories and laboratories, in processes also subject to substantial regulation. Medicines on sale also need to be safe and effective, but the role of pharmacies is now insignificant in this area as they only prepare a small number of prescribed formulae. For most medicines, control is achieved by industrial production, with the incentives provided by manufacturers' reputations, and regulation which includes the authorization of new medicines.

All the same, in most developed countries, pharmacies have retained a professional status, with entry barriers and organizational controls that depart substantially from a free market regime. Justification of this professional status is usually based on three types of objective: (1) use of the right medicines in each individual case; (2) availability of the necessary medicines; (3) gatekeeping, either in the control of certain drugs or, more recently, some type of economic optimization. With the exception of use, the other objectives (and also use in the case of antibiotics) are associated to externalities. Let us briefly examine these objectives to see to what extent they have are justified in today's economy.

\section{V.1. Services}

\section{Health advice}

In their traditional form, pharmacies have always supplied customers with a wide range of information, including the diagnosis of minor complaints that can be treated with over-thecounter medicines, and advice on the proper dosage and use of medicines. Obviously, the quality of these information services is of vital importance and users find it difficult to evaluate such quality. Furthermore, it is widely believed that the increasing strength, variety and cost of medicines has made proper selection and control more important.

\footnotetext{
${ }^{19}$ For more detail on the arguments developed in this section, see Arruñada (2001)
} 
However, it is unclear whether the dual control of prescriptions by both doctors and pharmacies is really efficient and, if not, who should carry out this control. Furthermore, even if this doubt were resolved in favor of pharmacists, it would still be necessary to determine what type of pharmacy would be required to provide such advisory services and how they should be provided. It is possible that pharmacies as we know them today are no longer necessary and that the production of information should be carried out separately from the physical distribution of medicines. This debate on the design of pharmacies links up with the possibilities of providing pharmaceutical services via the Internet, which would dilute the importance of the economies of scope that perhaps still exist amongst the logistical and advisory functions of conventional "brick and mortar" pharmacies.

In addition, health care experts insist that modern pharmacies should have more human and physical resources than is often the case. Examples of such resources are the constant presence of at least one qualified pharmacist, users' clinical data bases integrated with those of the rest of the health system, and enough space to guarantee confidentiality for users. In many European countries, traditional pharmacies find it difficult to meet these requirements because regulations impede them from reaching economies of scale.

\section{Availability}

Most countries have given priority to nationwide provision of pharmaceutical services. They have therefore regulated the opening of new pharmacies and have manipulated prices and margins in order to guarantee profitability and therefore survival for even the most remote pharmacies. This has led to serious imbalances because there has been no adaptation to changes in demand and in technology, caused by urbanization and new means of transportation.

As a result of such changes and of the difficulties of regulation, in most of Europe pharmacies are often too small and their density is excessive. Furthermore, this fragmentation of pharmacies disregards the fact that the lower costs of public transport have drastically altered the size of the relevant markets. If it is efficient for many rural users to travel 40 or $60 \mathrm{~km}$ to receive primary health care, it is difficult to understand why the organization and the cost of a pharmaceutical distribution system should be manipulated so that the same rural (and, increasingly, old town) consumers have access to a pharmacy near their home.

The way in which distribution is carried out for unregulated and widely consumed products provides a useful empirical comparison, of special interest for showing the opportunities which

are missed by the current system. All over Europe, small towns are visited—on at least a weekly basis - by distributors of fruit, meat, frozen goods, fresh bread and other foods who, having invested in suitable vehicles, make a living from running such mobile shops. Such traveling services would not be sufficient to meet urgent needs but would at least meet the demand of those towns which today have no pharmaceutical service at all, let alone an emergency service. Territorial coverage, if necessary, could therefore be achieved by using a number of methods, such as mobile sales points, mail orders, the Internet and setting up dispensaries, and not necessarily by keeping small pharmacies open. Such methods would serve not only rural users but all people who are unable to travel, and would do so without sacrificing any possible gatekeeping. 
Physical pharmaceutical distribution is a necessary condition for obtaining access to medicines. It is therefore logical for such distributors to carry out certain public gatekeeping functions to ensure that access complies with the law. In particular, pharmacies have traditionally been assigned the task of controlling access to dual-purpose substances, such as narcotics and stimulants, which can be used not only as medicines but also for other purposes that are considered improper.

In a similar way, pharmacies can be used to contain the moral hazard inherent in controlling pharmaceutical expenditure by carrying out financial control of prescriptions, either by dispensing substitutes for costly prescriptions or forcing doctors to prescribe generics. The aim is that only the drugs that are necessary should be consumed for each complaint, avoiding the tendency to consume unnecessarily costly medicines, specially when a third party pays the bill, or ones that might generate negative externalities, such as the use of too powerful antibiotics.

\section{V.2. Policy}

This analysis of the nature and evolution of pharmaceutical retailing leads to conclude that there are two relevant aspects - private and public. With private services, the essential element is the substitution that has taken place throughout the $20^{\text {th }}$ century regarding quality guarantees. Professional safeguarding of quality has become less important with the development of industrial drugs and wider access to medical prescription. With regard to public services, modern methods of communication have made the need for physical presence unnecessary in achieving territorial coverage.

The current structure of the sector is, therefore, defective in many European countries because it still aims to avoid private information asymmetries and to guarantee territorial coverage, leading to inefficient fragmentation. If there is any justification for restricting competition, it should be based on the objective of achieving public services associated with the sequential control of health activity, especially perhaps from en economic point of view.

To avoid the inefficiencies seen in the sector today and to promote the public service objectives, it would be necessary to renovate the regulations, which should aim to promote larger pharmacies and allow the use of distance-service technologies, both by mail and online. With respect to control and gatekeeping functions, there is no apparent reason why the control exerted by a distance or online pharmacy should be less effective than that performed by a conventional pharmacy. On the one hand, the larger size of the former makes them easier to supervise and gives them a greater incentive to comply with the law. On the other hand, control of both the doctor giving the prescription and the purchaser could be more effective than in conventional pharmacies in which, for example, purchases are often made on behalf of the patient. In addition, computerization of prescriptions would reduce the current risk of forgeries.

A case in point is that of the European policy on online pharmacies. ${ }^{20}$ The European Commission and most governments declare that they are committed to promoting innovation in this field but they do not adopt effective measures. On the contrary, concern over consumer

20 See on this Arruñada (2004). 
safety is used as the argument against liberalization of online sales of medicines. Meanwhile, sales by rogue sites keep increasing, given the difficulties for effective enforcement. The end result is that prohibition hinders the existence of reliable online operations and not only protects conventional pharmacies but also, indirectly, rogue sites, as an increasing number of customers use them to buy legal medicines that could be provided by reliable online operators. A report on competitiveness commissioned by the European Commission concluded that "the diffusion of cost-effective ways of dispensing drugs could be encouraged, relying on mail-order pharmacies and on the potential gains in productivity that are associated with the new Information and Communication Technologies" (Gambardella, Orsenigo and Pammolli, 2000, 61). The sector is almost undeveloped in Europe, however, because only three countries (Denmark, Netherlands and the UK) allow distance selling of medicines. Furthermore, the pioneer online pharmacies established in these countries are in theory allowed to sell to buyers from other countries of the EU by the e-commerce directive (Bordoni, 2001, 2). National authorities are increasingly constraining such practice, however, as shown by the DocMorris.com case (Zwick, 2001). ${ }^{21}$ Meanwhile, the EU is busy devising grand plans and implementing costly infrastructures of doubtful value, such as the "eEurope An Information Society for All" initiative (European Commission, 1999, 14; 2001). In summary, it seems that European governments are striving to facilitate e-commerce by all means except, in the case of e-pharmacy, for removing the regulatory constraints that make it still impossible in most of the EU.

\section{Conveyancers}

Intervention by various kinds of lawyers is legally required to contract real estate in many countries. In other cases, including 16 states in the USA, there is no legal requirement but lawyers are the only professionals allowed to help in writing such contracts. Notaries enjoy a similar monopoly all over Europe, with the exceptions of Ireland, the UK and Scandinavia but including former Socialist countries, as well as in Latin America. Their position is grounded on the legal requirement of notarisation to file all sorts of documents in public registers and is protected by a full set of restrictions, including a closed number of notaries, fixed prices and prohibitions on advertising and organization of notary offices.

Various international initiatives have recently argued that mandatory intervention by civil law notaries is inefficient. In its Doing Business 2004, the World Bank suggested that notaries are the main culprits for the greater cost and longer duration of company incorporations in civil law countries (World Bank, 2004, pp. 26-27). Together with pharmacies, notaries figured prominently as the most regulated profession in the study commissioned by the European Union

21 The case has been ruled in favour of Doc.Morris by the European Court of Justice in its judgment of December 11 $1^{\text {th }}, 2003$ (Case C-322/01 Deutscher Apothekerverband eV v 0800 DocMorris NV and Jacques Waterval). As a consequence, national law may not prohibit mailorder sales of to non-prescription drugs. 
Competition DG on the liberalization of professions (Monti, 2003, 2; Paterson, Fink, and Ogus, 2003, pp. 51-57).

Both initiatives made a good case but also forgot two key points. By focusing on notaries, the Doing Business report disregards the fact that a similar argument can be made about lawyers when their intervention is still de iure or de facto mandatory. By paying insufficient attention to the nature of the service in question, the EU risks advancing costly reforms that might perpetuate many of the current inefficiencies, as shown by the mixed results of liberalization efforts. For instance, the Netherlands liberalized most notaries' prices since 1999 and allowed some freedom of entry into each other's reserved markets, but results have been poor (Kuijpers, Noailly and Vollaard, 2005; and Nahuis and Noailly, 2005).

Instead of partial liberalizations, of dubious effects, what is needed is to adapt public policy to current circumstances. The starting point is to evaluate under which titling systems and for which transactions mandatory intervention is still necessary. The demand for conveyancing services has changed substantially with the development of land titling systems and the radical transformations that have taken place in the parties, technology and transactions of the conveyancing market. Such changes in both institutions and markets have made intervention by law professionals less necessary, especially in standard residential transactions. Let us briefly explain why. ${ }^{22}$

At the institutional level, states have developed titling systems which effectively make property contracts or property rights public, reducing the threat that hidden property rights previously posed to acquirers. This destroyed most of the demand for those conveyancing services that, to some extent, provided a substitutive service, avoiding title conflicts, designing title guarantees and acting as title depositories. Public titling systems made these services unnecessary with respect to rights held by third parties. Recording of deeds made lawyers and notaries redundant as depositories of deeds and reduced their demand for designing title guarantees. And registration of rights fundamentally modifies their role in gathering the consent of affected third parties: given that under registration, courts adjudicate conflicting rights by applying a rule of liability (Arruñada, 2003), parties tend to encourage conveyancers and title examiners to disguising before the register instead of preventing such title conflicts, a change that further reduces the former gatekeeping function of these professionals. More recently, information technologies are competing with notaries as document authenticators.

At the market level, the emergence of large firms in mortgage lending, real estate development and mediation of property transactions has reduced the comparative advantage of conveyancers because such firms are in a good position to guarantee quality to their customers and to reach economies of scale and lower costs in the preparation of contracts. A similar consequence has resulted from changes in the nature of transactions, which have become more standardized with the development of mass markets and mandatory legislation, both of which reduce the demand for tailoring contracts to individual needs.

In sum, public titling systems have made qualified conveyancers less useful with respect to rights held by third parties. At the same time, large, reputable parties and standardized transactions have made such professional conveyancing less necessary and effective for protecting parties to private contracts against each other. Mandatory intervention by law

22 This is based on Arruñada (2003). 
professionals should therefore be reconsidered, especially for standard contracts. Alternative procedures for entering individual contracts and other standard documents in land and company registers should be established. These should include steps for checking parties' identities and capacities more effectively and should cover the use of electronic documents. The State may also play a greater role in drawing up standard-form default contracts for real estate conveyance, mortgage loans and company registration.

Recent reforms and trends are moving in this direction, with lawyers being used only in transactions in which they are really needed. In most of the US, lawyers do not intervene in most residential transactions and mortgages, and title companies, through lay employees, search the title, prepare the documents and close the transaction. These tasks have also been performed in England by licensed conveyancers since 1986. The fact that the US uses recording of deeds and England registration of rights suggests that these changes are viable under both systems of public titling.

\section{Conclusion}

Professional services are characterized by information asymmetries, economies of scope and externalities. To resolve conflicts of interest, they require special organizational formulas, based on deferred and variable compensation, self-selection and, when positive externalities are necessary, competitive restraints. In principle, a set of criteria and organizational design patterns could be used for assessing, managing and regulating all types of professional organization, whether public or private, competitive or monopolistic. Competitive restraints, however, entail substantial risks, one of the main ones being that they tend to outlast their useful life. This point has been illustrated here by examining pharmacists and conveyancers, two professions for which the existing restraints may today be dysfunctional to the extent that the services that might have made such restraints necessary are provided by other public and private agents. Greater liberalization is therefore advisable, especially for standard services, and not only from a public interest perspective but also from the private interest perspective of the professions themselves. If my argument is correct, liberalization would encourage professionals to quit providing trivial services and focus on those which make efficient use of professionals' knowledge and add greater value to users, what nowadays seems to be the only sustainable strategy in a dynamic society. 


\section{Bibliography}

ARRUÑADA, B. (2004) “Quality Safeguards and Regulation of Online Pharmacies”, Health Economics, 13, 4, 329-344.

ARRUÑADA, B. (2003) "Property Enforcement as Organized Consent”, Journal of Law, Economics, and Organization, 19, 2, 401-444.

ARRUÑADA, B. (2001) "Las farmacias y el paso de los siglos", Revista de Administración Sanitaria, 5, 19, 119-134.

ARRUÑADA, B. (2000) "Audit Quality: Attributes, Private Safeguards and the Role of Regulation", The European Accounting Review, 9, 2, 205-24.

ARRUÑADA, B. (1999a) The Economics of Audit Quality: Private Incentives and the Regulation of Audit and Non-Audit Services, Boston and Dordrecht, Kluwer.

ARRUÑADA, B (1999b). "The Provision of Non-Audit Services by Auditors: Let the Market Evolve and Decide", International Review of Law and Economics, 19, 4, 513-531.

ARRUÑADA, B. (1992) "Profesionales del monopolio", Revista de Economía, 14, 4 th trimester, 95-101.

ARRUÑADA, B., and V. ANDONOVA (2005) "Market Institutions and Judicial Rulemaking", in Ménard, C. and Shirley, M. M. (eds.) Handbook of New Institutional Economics, Dordrecht, Springer, 229-250.

ARRUÑADA, B., and V. ANDONOVA (2004) "Cognition, Judges and Market Order”, Universitat Pompeu Fabra, Department of Economics and Business, Economics and Business Working Paper Series 768, July (http://www.econ.upf.es/cgi-bin/onepaper?768).

BECKER, G. S., and G. J. STIGLER (1974) "Law Enforcement, Malfeasance, and Compensation of Enforcers", Journal of Legal Studies, 3, January, 1-18.

BORDONI, L., rapporteur (2001) "Issue Paper”, Working Group Manufacturing "Consumer Goods Industry", Conference on The E-conomy in Europe, Brussels, 1-2 March (http://europa.eu.int/comm/enterprise/events/e-economy/doc/manufacturing2 paper.pdf, visited June 8, 2001).

CARR, J. L., and G. F. MATHEWSON (1990) "The Economics of Law Firms: A Study in the Legal Organization of the Firm", Journal of Law and Economics, 33, October, 307-330.

CHRISTENSEN-SZALANSKI, J. J. and C. F. WILLHAM (1991) "The Hindsight Bias: A MetaAnalysis", Organizational Behavior and Human Decision Processes, 48, 147-168.

DARBY, M. R., and E. KARNI (1973) "Free Competition and the Optimal Amount of Fraud", Journal of Law and Economics, 16, 67-88. 
EUROPEAN COMMISSION (2001) "E-Europe: An Information Society For All. Objective 3 Stimulate the use of Internet: Accelerating e-commerce", (http://europa.eu.int/information_society/eeurope/index_en.htm, visited June 8, 2001).

EUROPEAN COMMISSION (1999) "E-Europe: An Information Society For All”, Communication on a Commission Initiative for the Special European Council of Lisbon, 23 and 24 March 2000, COM(1999) 687 final, December 1999 (http://europa.eu.int/information_society/eeurope/news_library/pdf_files/initiative_en.pdf, visited June 8, 2001).

EVANS, L., M. LAURILA, and R. PASERMAN (2004) "Professional Services: More Competition, More Competitiveness, More Consumer Orientation", Ninth EU Competition Law and Policy Workshop: The Relationship between Competition Law and (Liberal) Professions, European University Institute, Florence, 11-12 June 2004.

FAMA, E. F., and M. C. JENSEN (1983a) "Separation of Ownership and Control", Journal of Law and Economics, 26, June, 301-325.

FAMA, E. F., and M. C. JENSEN (1983b) "Agency Problems and Residual Claims", Journal of Law and Economics, 26, June, 327-349.

FELDSTEIN, P. J. (1988) Health Care Economics, $3^{\text {rd }}$ ed., Wiley, New York.

FISCHHOFF, B. (1975) "Hindsight $\neq$ Foresight: The Effect of Outcome Knowledge on Judgment under Uncertainty", Journal of Experimental Psychology: Human Perception and Performance, 1, 288-299.

FITZSIMMONS, J. A., and R. S. SULLIVAN (1982) Service Operations Management, McGraw-Hill, New York.

GAMBARDELLA, A., L. ORSENIGO and F. PAMMOLLI (2000) "Global Competitiveness in Pharmaceuticals: A European Perspective", Report Prepared for the Directorate General Enterprise of the European Commission, November 2000 (http://pharmacos.eudra.org/F2/pharmacos/docs/Doc2000/nov/comprep_nov2000.pdf, visited June 8, 2001).

GILSON, R. J., and R. H. MNOOKIN (1985) "Sharing Among the Human Capitalists: An Economic Inquiry into the Corporate Law Firm and How Partners Split Profits", Stanford Law Review, 37, January, 313-392.

KLEIN, B., and K. LEFFLER (1981) "The Role of Market Forces in Assuring Contractual Performance", Journal of Political Economy, 89, August, 615-641.

KRAAKMAN, R. H. (1986) “Gatekeepers: The Anatomy of a Third-Party Enforcement Strategy”, Journal of Law, Economics and Organization, 2, 53-105.

KUIJPERS, N., J. NOAILLY and B. VOLLAARD, "Liberalisation of the Dutch Notary Profession: Reviewing its Scope and Impact," CPB Netherlands Bureau for Economic Policy Analysis, Discussion Paper, no. 93, September 2005.

LAZEAR, E. P. (1979) “Why Is There Mandatory Retirement?”, Journal of Political Economy, 87, December, 1261-1284.

LEVITT, T. (1972) "Production Line Approach to Services", Harvard Business Review, September-October, 41-52. 
LEVITT, T. (1976) “The Industrialization of Services”, Harvard Business Review, SeptemberOctober, 63-74.

MONTI, M. (2003) "Competition in Professional Services: New Light and New Challenges", Bundesanwaltskammer, Berlin, 21 March.

NAHUIS, R., and J. NOAILLY (2005), "Competition and Quality in the Notary Profession," CPB Netherlands Bureau for Economic Policy Analysis, Discussion Paper, no. 94, September 2005.

NELSON, P. (1970) "Information and Consumer Behavior", Journal of Political Economy, 78, 311-329.

PATERSON, I., M. FINK, and A. OGUS (2003) "Economic Impact of Regulation in the Field of Liberal Professions in Different Member States", Institute for Advanced Studies, Vienna, January, Final Report-Part 1 (available at http://europa.eu.int/comm/competition, accessed May 10, 2004).

POSNER, R. A. (1995b) "What Do Judges Maximize", in Overcoming Law, Harvard University Press, Cambridge, MA.

SHAPIRO, C. (1983) "Premiums for High Quality Products as Returns to Reputations", Quarterly Journal of Economics, 98, November, 659-679.

SHAPIRO, C., and J.E. STIGLITZ (1984) "Equilibrium Unemployment as a Worker Discipline Device", American Economic Review, 74, June, 433-444.

STEPHEN, Frank H. (2004) "The Market Failure Justification for the Regulation of Professional Service Markets and the Characteristics of Consumers", Ninth EU Competition Law and Policy Workshop: The Relationship between Competition Law and (Liberal) Professions, European University Institute, Florence, 11-12 June 2004.

WATTS, R. L., and J. L. ZIMMERMAN (1979) "The Demand for and Supply of Accounting Theories: The Market for Excuses", The Accounting Review, 54, 273-305.

WATTS, R. L., and J. L. ZIMMERMAN (1986) Positive Accounting Theory, $2^{\text {nd }}$ ed., PrenticeHall, Englewood Cliffs, NJ.

WILLIAMSON, O. E. (1983) "Credible Commitments: Using Hostages to Support Exchange", American Economic Review, 73, 519-40.

WORLD BANK (2004) Doing Business in 2004: Understanding Regulation, Washington DC, World Bank and Oxford University Press.

ZWICK, S. (2001) "Médecines sans Frontières: A Dutch Dotcom that Fills Prescriptions for its Neighbors Challenges Germany's Strict Regulations", Time Europe, June 8 (http://www.time.com/time/europe/biz/column/0,9868,101418,00.html, visited June 8, 2001. 